\title{
Cardiac Manifestations of Twin-to-Twin Transfusion Syndrome
}

\author{
Nicky Manning and Nick Archer \\ Fetal Cardiology, Oxford University Hospitals, Oxford, UK
}

\begin{abstract}
This review addresses the physiology of monochorionic diamniotic (MC/DA) twins and the potential for twin-twin transfusion syndrome (TTTS). It focuses on the underlying cardiovascular pathophysiology of TTTS and the cardiovascular impact of TTTS for both the recipient and the donor twin. It explains the principles for assessment and monitoring of these cardiovascular changes and how these may be used to guide pregnancy management. Finally, it describes the effect of treatment on the altered hemodynamics and how this can influence pregnancy and perinatal management, as well as longer-term follow-up.
\end{abstract}

Keywords: monochorionic twins, twin-twin transfusion syndrome, cardiac function, cardiomyopathy, outflow tract obstruction

Monochorionic (MC) twins are recognized to be at increased risk for 'primary' structural heart disease even in the absence of TTTS; figures quoted are for between $4-11 \%$ for at least one of a twin pair, even in the absence of TTTS; this increased risk is for all cardiac lesions, including for laterality defects that are otherwise considered to be rare. Structural cardiac lesions identified in these monozygotic twins are usually discordant even though the twins are considered to be genetically identical (AlRais et al., 2011; Weber \& Sebire, 2010); mechanisms for discordancy are explained in terms of post-zygotic events (Edlow et al., 2011; Silva et al., 2011).

TTTS occurs in 10-15\% of MC/DA twins and, in its more advanced form and without treatment, is associated with a very high morbidity and mortality for one or both twins. Altered hemodynamics associated with TTTS are manifested in the heart; functional cardiovascular changes, although subtle, are present from very early in the disease process (Baschat et al., 2011) and may be demonstrated in the earliest stages of TTTS (Michelfelder et al., 2007), even before the diagnosis of TTTS is made (Zanardini et al., 2014). It is suggested that increased nuchal translucency, with or without abnormal ductus venosus waveforms in early gestation, is a reflection of early hemodynamic changes (Matias et al., 2010). Prompt diagnosis of chorionicity is essential in order to ensure appropriate monitoring during pregnancy; interestingly, failure to identify monochorionicity may still occur in up to $33 \%$ of twin pregnancies and, although accuracy is increasing, there is still room for improvement (Baud et al., 2014).
Evolution of functional heart disease is partly explained as a consequence of unequal circulating volumes, causing both systolic and diastolic dysfunction, particularly in the recipient twin. These functional changes may further lead to the development of 'acquired' structural heart disease, again particularly, but maybe not exclusively, in the recipient twin. The cardiovascular complications of TTTS are an important factor contributing to the morbidity and mortality in MC twins.

The physiology of MC/DA twins is effectively that of a single placenta in two separate sacs; within the placenta there are anastomoses, arteriovenous (AV), arterioarterial (AA), and venovenous (VV); as a result of these anastomoses, inter-twin transfusion virtually always occurs. AV vascular anastomoses along the chorionic plate allow unidirectional flow from one twin to the other, with the potential to create an imbalance of flow through this high resistance capillary bed. In $85-90 \%$ of MC twins this is a balanced phenomenon due to the presence of protective superficial bidirectional anastomoses in the form of low resistance AAs that can compensate for any imbalance resulting from the unidirectional flow in the AV

RECEIVED 8 January 2016; ACCEPTED 3 March 2016. First published online 18 April 2016.

ADDRESS FOR CORRESPONDENCE: Dr Nicky Manning, Department of Fetal Cardiology and Fetal Medicine, Level 6, Women's Centre, Oxford University Hospitals, Headley Way, Oxford, OX3 9DU, UK. E-mail: nicky.manning@ouh.nhs.uk 
anastomoses (Lewi et al., 2013). The significance of the VV anastomoses is less well understood; they are relatively uncommon, present only in $20 \%$ of MC placentas, also with bidirectional flow; they are found more frequently in TTTS placentas and are therefore considered to play a role in the development of this process (Zhao et al., 2014), especially in the absence of AA anastomoses; they are not detectable during antenatal ultrasound examination and so their clinical impact is hard to monitor (Zhao et al., 2015); in effect, the MC placenta consists of three parts, two of which belong to each twin individually and a third part which is shared and supplied by the AV anastomoses (Lewi et al., 2013).

In $10-15 \%$ of $\mathrm{MC}$ twins there is unequal volume distribution, maybe due to fewer protective AA anastomoses (de Villiers et al., 2012). This imbalance is the basis for TTTS, perhaps more accurately described as oligopolyhydramnios sequence (TOPS), as usually there is no significant difference in hemoglobin concentration (Saunders et al., 1991). This unequal volume distribution not only leads to altered hemodynamics for both twins but also, as a consequence of the shared and mixed circulation, the wellbeing of one twin critically depends on that of the other (Lewi et al., 2013), raising specific issues in pregnancy management.

The etiology of TTTS is unknown, although it only affects MC twins; it usually presents between 15 and 25 weeks, although it can be seen earlier or later, sometimes with an acute onset. It is essentially hemodynamic, affecting both twins, with activation of additional hormonal factors; it is described both as a progressive disease and also as potentially devastating but with remarkable powers for recovery following treatment (Moon-Grady, 2014). Progression is unpredictable, thus pregnancies likely to need treatment may be hard to identify. It is acknowledged that clear guidelines for treatment are essential, especially as treatment, although improving, is still considered to be relatively high risk (Diehl et al., 2014).

The hemodynamics in TTTS are those of chronic imbalance of circulating volumes with hypervolemia in the recipient and hypovolemia in the donor. The consequent pathophysiology of TTTS is determined by the physiological responses to chronic volume inequality and it is these that can cause both functional and acquired structural cardiac anomalies, particularly in the recipient twin; meanwhile donor twins are rarely affected by significant functional anomalies (Michelfelder et al., 2007; Moon-Grady, 2014). Most of the functional changes are considered to be reversible with successful in utero treatment (Moon-Grady, 2014), but there is still much to be understood on this subject.

For the recipient, there is increased preload (volume) with an absolute increase in circulating volume compared to that of the donor, with significantly higher cardiac output as measured by umbilical venous volumetric flow (Yamamoto et al., 2007); hypervolaemia leads to the release of natriuretic peptides, atrial natriuretic protein (ANP) and brain natriuretic protein (BNP), presumed to be stimulated by myocardial stretch. Both ANP and BNP are biomarkers associated with heart failure; elevated levels are found in the amniotic fluid of the recipient, suggesting the presence of myocardial damage (Habli et al., 2010; Van Mieghem et al., 2010), and the levels of these peptides appear to increase with progressive TTTS stages (Habli et al., 2010). Increased levels of cardiac troponin are also seen in the recipient, adding further support to the theory of myocardial damage in the recipient (Van Mieghem et al., 2010); a consequence of this hormonal stimulation is a diuresis, producing polyuria and polyhydramnios.

The recipient is also subjected to an increased afterload in the form of increased resistance, as demonstrated by a 1.6-2.8-fold increase in the velocity of tricuspid regurgitation compared to the expected value, reflecting high right heart pressure in the presence of fetal hypertension (Mahieu-Caputo et al., 2003). Recipient hypertension is attributed to the presence of various vasoactive mediators, particularly endothelin, but also the consequence of inappropriate renin-angiotensin stimulation. Endothelin is a powerful vasoconstrictor causing hypertension and is assumed to contribute to the development of biventricular hypertrophy both directly, as a result of the increased pressure, and indirectly, by stimulating cardiac myocytes involved in cardiac remodeling. The source of endothelin is probably partly from the placenta and partly from the donor via the vascular communications. The renin-angiotensin system (RAS) is 'downregulated' in the recipient's kidneys, but work has shown that the levels are as high as in the donor (Mahieu-Caputo et al., 2005); it is assumed that this is mainly due to transfer from the donor, although there is evidence of increased renin production in the recipient's placental territory (Galea et al., 2008). It is relevant that, as a consequence of the placental anastomoses, one twin is exposed to the endocrine environment of the other. All these factors explain the development of significant myocardial ventricular hypertrophy, out of proportion to simple volume overload (Mercanti et al., 2011). A consequence of this progressive cardiomyopathy is an increase in overall heart size, a reduction in myocardial compliance, atrioventricular valvar regurgitation, and abnormal venous Dopplers (Stirnemann et al., 2010).

For the donor there is an absolute reduction in the circulating volume leading to chronic under perfusion, resulting in oliguria and oligohydramnios; hypoperfusion stimulates upregulation of the RAS to try to maintain perfusion, resulting in increased vascular resistance with smooth muscle hypertrophy. The donor's circulation is underfilled but hyperdynamic; increased vascular resistance, including in the placenta, may lead to intrauterine growth restriction (IUGR), cerebral redistribution and abnormal arterial Doppler assessment. Studies suggest that usually the heart of the donor is functionally normal and that any diastolic 
TABLE 1

Quintero Staging of TTTS is the Established Framework for Staging TTTS

\begin{tabular}{ll}
\hline Stage I & Donor bladder visible \\
\hline Stage II & No donor bladder \\
& Normal Doppler assessments \\
\hline Stage III & Abnormal Doppler assessments \\
& For donor: \\
& -AEDF/REDF in donor umbilical artery \\
& $+/-$ \\
& For recipient: \\
& -Abnormal DV flow \\
& -Pulsatile umbilical vein \\
\hline Stage IV & Hydrops in one twin \\
\hline Stage V & Death of one/both twins \\
\hline Note: AEDF; absent end diastolic flow; REDF: reversed end diastolic flow;
\end{tabular}
DV: ductus venosus.

dysfunction is assumed to be due to the effects of severe IUGR (Van Mieghem et al., 2010).

Historically, and currently, TTTS has been classified according to the Quintero as summarized in Table 1.

The presentation of TTTS can be mixed and thus not fit clearly into this staging system; there may be abnormal Doppler assessments while the donor still has a demonstrable bladder, and it is widely acknowledged that progression is notoriously difficult to predict (Stirnemann et al., 2010; Ville, 2007). A limitation of the Quintero staging is that it does not reflect the whole situation; in particular, it only partly quantifies cardiac involvement. Stages 1 and 11 are a measure of renal perfusion, and stages 111 and $\mathrm{IV}$ are a consequence of cardiovascular compromise. It is argued that since TTTS is essentially a cardiovascular disorder, there is a role for defining cardiac dysfunction, thus quantifying cardiac involvement and severity of disease; in doing so, the aim is to improve prediction of progression and thus identification of pregnancies that might benefit from treatment. If used in conjunction with Quintero staging, this is a tool to refine the staging process, thus contributing to pregnancy management (Habli et al., 2008; Michelfelder et al., 2007). However, this is a subject for debate, particularly between fetomaternal specialists and cardiologists (Quintero, 2010; Rychic et al., 2010; Stirnemann et al., 2010; Ville, 2007).

Diastolic dysfunction has an important influence on the preservation of the fetal circulation; in the recipient twin, diastolic dysfunction precedes systolic dysfunction, with the right ventricle involved before the left (Rychic et al., 2007); this process is considered by some to be specific to the hemodynamics of TTTS, thus distinguishing it from other complications of $\mathrm{MC} / \mathrm{DA}$ twins, including selective growth restriction (Moon-Grady et al., 2011). The E/A ratio refers to the ratio of the two peaks observed with pulsed wave Doppler across the atrioventricular valves; the $\mathrm{E}$ wave is the early passive diastolic filling, dependent on ventricular wall relaxation, and in the normal fetal heart is smaller than the later A wave of the active phase of diastolic filling. Changes in the $\mathrm{E} / \mathrm{A}$ ratio reflect ventricular diastolic dysfunction, and
TABLE 2

Quantifiable Functional Changes in the Recipient Twin

\begin{tabular}{lll}
\hline 1 Ventricular myocardial hypertrophy & $\begin{array}{l}\cdot \text { Right ventricle before left } \\
\cdot\end{array}$ \\
\hline 2 Increased heart size & $\begin{array}{l}\cdot \text { Hypertrophy not dilatation } \\
\cdot \text { Increased C:T ratio }\end{array}$ \\
\hline 3 Ventricular hypokinesia & $\cdot$ Increased MPI \\
\hline 4 Atrioventricular valvar dysfunction & $\begin{array}{l}\cdot \text { Regurgitation } \\
\cdot\end{array}$ \\
& $\cdot$ TV before MV \\
& - Acceleration across the RVOT \\
\hline 5 +/- RVOTO & $\cdot$ Pulmonary regurgitation \\
\hline
\end{tabular}

Note: $\mathrm{C}: \mathrm{T}$ ratio $=$ cardiothoracic; $\mathrm{TV}=$ tricuspid valve; $\mathrm{MV}=$ mitral valve; RVOT $=$ Right ventricular outflow tract.
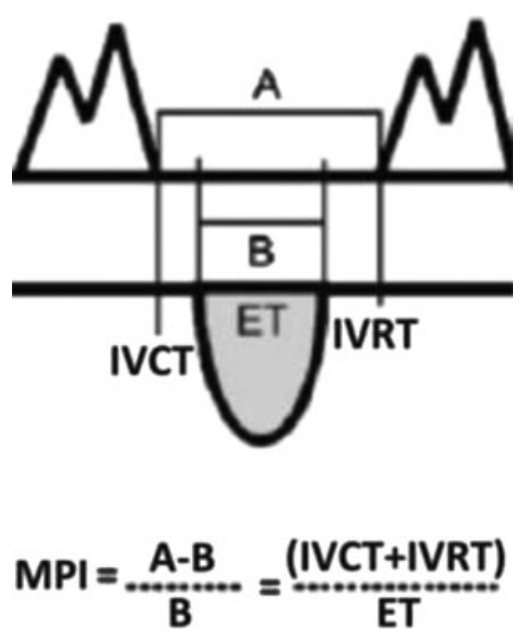

\section{FIGURE 1}

The Myocardial Performance Index (MPI) is a Doppler-derived measure of systolic and diastolic function; it reflects global myocardial performance by assessing the duration of flow through the atrioventricular and outflow tracts and can be used for serial evaluations. MPI rises as myocardial function decreases. Note: A $=$ time between atrioventricular (AV) valve closing and $A V$ valve opening. $B=$ ejection time (ET). IVCT = isovolumic contraction time. IVRT = isovolumic relaxation time.

the thickened myocardium with reduced compliance causes monophasic filling with the loss of the normal E/A ratio. The Myocardial Performance Index (MPI, Figure 1) also known as the TEI index, is a measure of global systolic and diastolic myocardial function and increases with myocardial dysfunction; although the donor may develop right ventricular diastolic impairment as a result of increased placental resistance, this is less quantifiable in terms of scoring.

The 'benefit' of these changes is that they can be used to produce a cardiovascular profile score with the purpose of quantifying the degree of cardiac involvement. There are various methods in use - an example is the CHOP score (Rychik et al., 2007), which aims systematically and objectively to calculate hemodynamic changes, particularly in the recipient twin. The higher the score, the greater the cardiac involvement (see Table 2), assumed to reflect 


\section{TABLE 3}

Parameters Used to Create the CHOP Cardiovascular Score for Quantifying TTTS

\begin{tabular}{|c|c|c|c|}
\hline $\begin{array}{l}1 \\
\mathrm{R}\end{array}$ & Ventricular elements & $\begin{array}{l}\text { a. Enlargement } \\
\text { b. Hypertrophy } \\
\text { c. Systolic function }\end{array}$ & $0-1-2$ \\
\hline $\begin{array}{l}2 \\
R\end{array}$ & Valve function & $\begin{array}{l}\text { Tricuspid regurgitation } \\
\text { Mitral regurgitation }\end{array}$ & $0-1-2$ \\
\hline $\begin{array}{l}3 \\
\mathrm{R}\end{array}$ & Venous Doppler & $\begin{array}{l}\text { a. Ductus venosus waveform } \\
\text { b. Mitral }+ \text { Tricuspid inflow }\end{array}$ & $0-1-2$ \\
\hline $\begin{array}{l}4 \\
\mathrm{R}\end{array}$ & Great vessel analysis & $\begin{array}{l}\text { a. RVOTO } \\
\text { b. Pulmonary valve regurgitation }\end{array}$ & $0-1-2$ \\
\hline $\begin{array}{l}5 \\
D\end{array}$ & Umbilical artery Doppler & $\begin{array}{l}\text { a. Normal } \\
\text { b. AEDF } \\
\text { c. REDF }\end{array}$ & $0-1-2$ \\
\hline
\end{tabular}

Note: $\mathrm{TR}=$ tricuspid regurgitation, $\mathrm{MR}=$ mitral regurgitation, $\mathrm{RVOTO}=$ right ventricular outflow tract obstruction, $A E D F=$ absent end diastolic flow, REDF $=$ reversed end diastolic flow. $\mathrm{R}=$ recipient, $\mathrm{D}=$ donor. Note: Very little contribution by the donor to this score.

increased severity of the TTTS process (see Table 3 ). It is, however, acknowledged that these assessments are difficult, time consuming and operator dependent, and reproducibility is not assured (Gapp-Born et al., 2014)

It is also important to acknowledge that Doppler assessments may be invalidated in the presence of structural heart disease, known to be increased in $\mathrm{MC}$ twins even in the absence of TTTS (AIRais et al., 2011). An abnormal ductus venosus waveform is seen with structural right heart lesions in mid gestation, whatever the cause (Berg et al., 2006).

Several studies have shown that changes in cardiac function can be demonstrated even before the development of TTTS, as judged by the presence of oligo/polyhydramnios. Stage 1 TTTS represents a heterogeneous group in whom $70-80 \%$, will remain stable or even regress spontaneously (Diehl et al., 2014; O’Donoghue et al., 2007; Ville, 2007); it has been observed that even early in stage l, up to $55 \%$ of fetuses have a degree of myocardial dysfunction, as demonstrated by an increased MPI (Stirneman et al., 2010). Maybe serial cardiovascular assessments enable differentiation within this group to distinguish those in whom TTTS is less likely to progress, thereby avoiding unnecessary treatment with its associated risks (Ville, 2007). By stage 1l, the incidence of recipient cardiomyopathy has been found to be as high as 65\% (Habli et al., 2012).

There is significant variation in different units around the world in terms of treatment protocols and developing international guidelines with the aim of optimizing outcome is in progress (Diehl et al., 2014). Cardiac assessment has the potential to help define specific criteria for laser therapy. However, it is acknowledged that as cardiovascular changes precede Quintero staging, there is a tendency to upgrade the severity of the disease, which may lead to earlier intervention as well as potentially producing falsely reassuring figures for success of treatment; but, as deterioration of the hemodynamics can be rapid, any help in identifying this earlier is desirable (Bebbington, 2010).
In summary, quantitative description of cardiac function is a challenge (Crispi \& Gratacos, 2012) and still controversial; different methods are described but all may be uncomfortable for the patient as well as for the clinician. The presence of polyhydramnios can lead to maternal discomfort, and both polyhydramnios and oligohydramnios can make accurate assessment technically difficult and reproducibility unreliable. Optimal methods for assessment remain subject to debate and further studies are in progress; a recently published paper from the Cincinnati group suggests that MPI is the method of choice (Villa et al., 2014). Quantified cardiovascular changes are a useful adjunct to Quintero staging in guiding management, but in busy clinical practice, the reality may be a compromise. Measurement of cardiac size, myocardial dimensions, subjective assessment of function, quantification of AV valve regurgitation, E/A ratios and evidence of outflow tract obstruction are all achievable and reproducible and can be monitored serially to assess progression or otherwise of the TTTS process.

There is interest in the measurement of biomarkers, particularly ANP and BNP, reflecting the degree of cardiac involvement or failure, with the advantage of reducing interobserver variability (Merz \& Gembruch, 2014; Miura et al., 2014); evidence suggests that when used in conjunction with assessment of cardiac dysfunction, quantification of amniotic fluid markers may identify fetuses particularly at risk of post-procedure demise (Van Mieghem et al., 2010).

Treatment for TTTS is covered by other contributors, but historically, amnioreduction was the treatment of choice. Although this gave symptomatic relief and the potential to reopen anastomoses (Senat et al., 2004), it often required multiple procedures and, vitally, did not treat the cardiovascular pathology, which therefore progressed (Barrea et al., 2005). In contrast, laser treatment, involving coagulation of the placental anastomoses, addresses the pathophysiology by disconnecting the two circulations and is therefore considered by many to cure TTTS, whatever the stage. Effectively converting the MC pregnancy to a dichorionic pregnancy, it prevents further inter-twin flow, ends the volume imbalance, and removes unwelcome vasoactive mediators from the other twin.

Laser treatment has a profound effect on fetal hemodynamics; for the recipient, the cardiac status worsens during the procedure, but several studies demonstrate that there is improved function over the following few days (Papanna et al., 2011). The donor experiences an acute relative volume overload manifested as an increase in cardiac size (Sueters et al., 2008), abnormal ductus venosus flow, sometimes transient hydrops (Gratacos et al., 2002) and with reappearance of end diastolic flow in the umbilical artery (Van Mieghen et al., 2009). There is encouraging evidence that using selective laser techniques, occluding donor to recipient communications before those of the recipient to donor, might facilitate achieving hemodynamic equilibrium by allowing transient net transfusion to the volume depleted 
donor (Chmait et al., 2014). The effect of treatment is regression of the cardiovascular pathology and improved myocardial performance (Habli et al., 2008); recovery may take longer in more severely affected pregnancies (Van Mieghem et al., 2013), but this is not the case in all series. It is possible that it is the duration rather than severity that is more relevant in terms of recovery (Van Mieghem et al., 2013). Cardiac function alone does not predict outcome (Eixarch et al., 2013) and much of the evidence is still conflicting and confusing, in spite of an exponential number of publications on the subject. The expectation following treatment, even for severe TTTS, is for improvement with likely resolution in utero; thus, selective fetal reduction is rarely indicated (Van Mieghen et al., 2010); an earlier study concluded that survival, particularly for the recipient, is likely to be compromised if treatment is delayed (Crombleholme et al., 2007); thus, early diagnosis, potentially facilitated by including assessment of cardiac function, is to be recommended.

Acquired structural cardiac anomalies are recognized in a proportion of treated pregnancies, presumed to be a consequence of the altered hemodynamics. They may require longer-term follow-up and even postnatal treatment; for the recipient, this is usually in the form of right ventricular outflow tract (RVOT) anomalies (Michelfelder et al., 2015); for the donor there is a suggestion of an increased incidence of coarctation of the aorta (van den Boom et al., 2010), although this is less well documented.

RVOT anomalies in the recipient may be in the form of valvar dysplasia, stenosis, regurgitation, or functional atresia; early involvement of the RVOT may be demonstrated by observing that the pulmonary valve annulus is equal in size to or smaller than that of the aortic valve, and this can progress to produce significant valvar pathology. It is not clear whether RVOT anomalies mirror the severity of the TTTS process, or whether the anomalies are simply due to altered hemodynamics or are a consequence of the vasoactive mediators. Little is known about the immediate and longer term impact on the tricuspid valve.

The prevalence of RVOT anomalies varies in different series but may be seen in some form in up to $20 \%$ of MC/DA twins, but only in recipient twins; between 9 and 12.5\% had persistent anomalies requiring postnatal treatment, in spite of otherwise successful treatment for the TTTS. In a recent study (Michelfelder et al., 2015), approximately 9\% of recipient twins had RVOT anomalies with pulmonary atresia seen more frequently than pulmonary stenosis, and although there was rapid improvement in utero in many, presumed to be due to improved RV function, up to $40 \%$ had persistent RVOT anomalies. This study also suggested that survival of those with RVOT involvement was lower than in those without and that the majority of cases with RVOT involvement were in Quintero stage lll or IV. Other studies have shown that pulmonary valve pathology is not necessarily associated with a worse outcome (Moon-Grady et al., 2011). It is recognized that these acquired structural lesions can progress even when function has improved, perhaps due to endothelial damage leading to the development of a dysplastic pulmonary valve (Michelfelder et al., 2015).

For the donor, there is a less well documented suggestion that the risk for developing coarctation of the aorta is increased (van den Boom et al., 2010), although the effect of treatment is unclear, and whether this is an example of 'primary' structural CHD in MC twins or a consequence of hypovolemia is not yet established (Pruetz et al., 2011)

Mechanisms for these specific anomalies are still speculative but are summarized in Table 4 and demonstrate the 'flow-grow' phenomenon for the growth of cardiac structures in utero. Identification of those likely to need postnatal treatment remains an important challenge (Michelfelder et al., 2015), and further work is needed to predict those that will have significant lesions after birth. In a recent study (Stagnati et al., 2015), accurate identification of recipient twins likely to develop RVOT anomalies was not achieved, but two factors appeared to predict a need for postnatal treatment: a shorter interval between onset of TTTS and the diagnosis of PS was associated with a higher chance of needing postnatal treatment, maybe due to poor adaptation to an acute onset of TTTS; antenatal severity was also a risk factor for requiring postnatal treatment. However, other studies observed that even functional pulmonary atresia usually recovers following successful laser treatment (Moon-Grady et al., 2011).

Coarctation of the aorta, more difficult to diagnose in the fetus whatever the cause, emphasizes the importance of careful postnatal cardiac assessment, including echocardiography, in survivors of TTTS (Van Miegen et al., 2010).

Postnatal cardiovascular sequelae (Table 5) are becoming more important as so many more twins are surviving, partly due to improved laser techniques and experience and partly due to improved early neonatal care (Akkermans et al., 2015). As discussed, the incidence of 'primary' structural heart disease is increased in MC twins, even without evidence of TTTS, and it has been reported that donor CHD is less frequently detected antenatally compared to that in recipient twins - 17\% compared to $43 \%$ (Pruetz et al., 2011). The risk factors and incidence for developing persistent pulmonary hypertension of the newborn in the recipient remains unclear, but the risk may be increased if there is a decline in cardiac function following treatment (Delsing et al., 2007; Takahashi et al., 2012). It is also relevant that if treatment for TTTS is successful earlier in the pregnancy, it may be difficult to identify which twin is which neonatally.

There is a logic for measuring blood pressure postnatally in both the donor and the recipient twin; growth restriction, myocardial dysfunction, chronic renal under perfusion, alteration in vascular stiffness, and prematurity are all risk factors for hypertension. Evidence for longer-term follow- 
TABLE 4

Possible Mechanisms for the Development of Acquired Structural Heart Disease

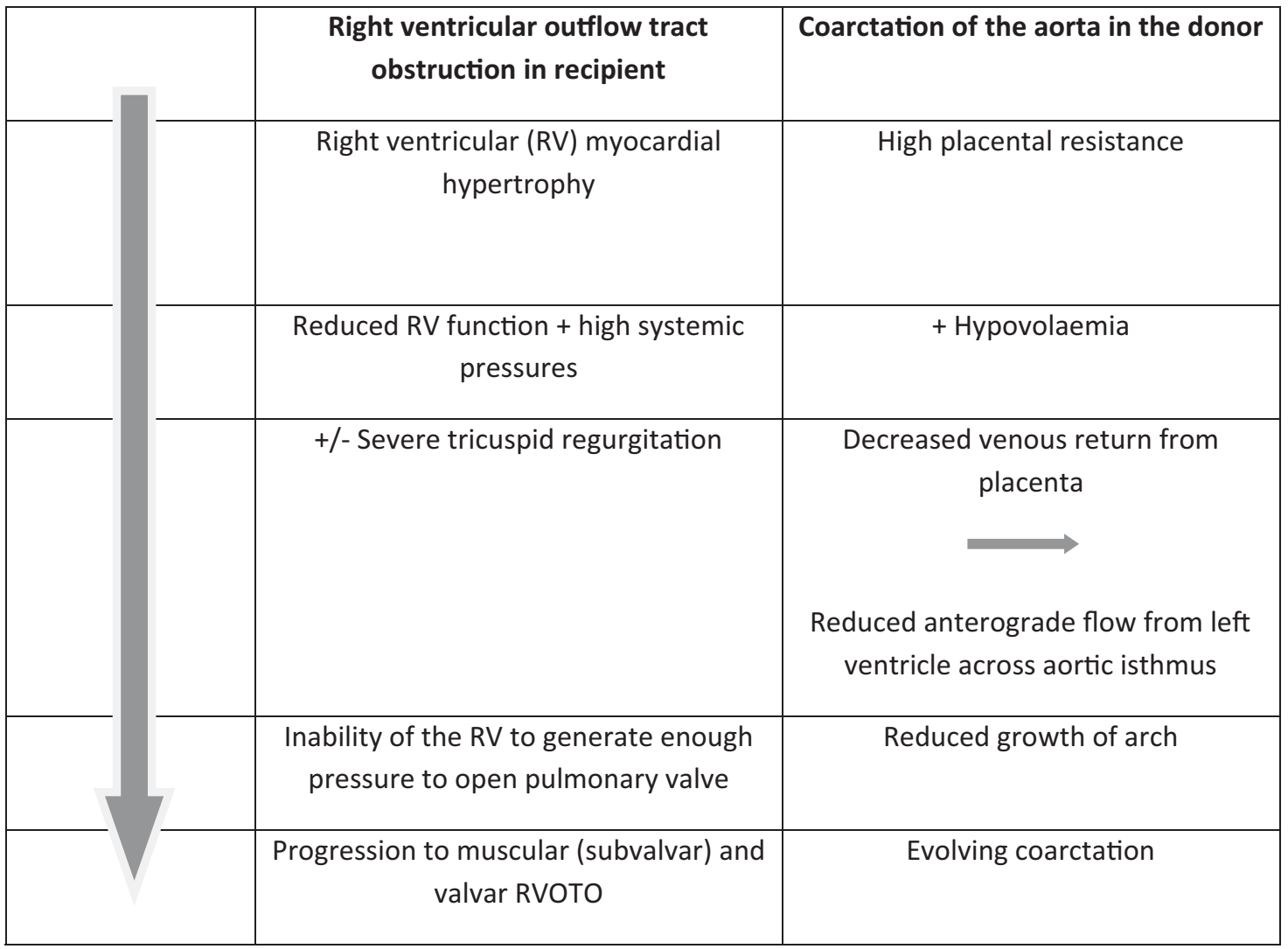

\section{TABLE 5}

Summary of Cardiovascular Considerations for Twins Surviving TTTS

\begin{tabular}{lc}
\hline For 'ex-recipient' & For 'ex-donor' \\
\hline $\begin{array}{l}\text { Resolving cardiomyopathy } \\
\text { Right ventricular outflow tract } \\
\text { obstruction -unpredictable } \\
\text { response to treatment }\end{array}$ & $\begin{array}{c}\text { Coarctation of the aorta - difficult } \\
\text { to exclude antenatally }\end{array}$ \\
$\begin{array}{l}\text { Blood pressure } \\
\begin{array}{l}\text { Persistent pulmonary } \\
\text { hypertension of the newborn }\end{array}\end{array}$ & $\begin{array}{l}\text { Blood pressure } \\
\text { Cardiac consequences of severe } \\
\text { IUGR }\end{array}$ \\
\hline
\end{tabular}

up, in accordance with the Barker hypothesis (Sueters et al., 2008) is interesting and requires more work; both twins are subjected to risk factors for lasting cardiovascular changes, which could predispose to hypertension.

A recent study found that both systolic and diastolic blood pressures were still increased at the age of 2 years, with no difference as to whether they were the donor or recipient (Pruetz et al., 2015). By the age of 10 years, the message is more encouraging and two recent studies have shown no significant myocardial dysfunction in either twin, even when there had been severe myocardial dysfunction in utero (Gardiner et al., 2014; Herberg et al., 2014), thus demonstrating the remarkably successful mechanisms for myocardial preservation, with or without remodeling, even after severe TTTS (Herberg et al., 2006). Longer-term consequences of smooth muscle hypertrophy and increased vascular stiffness, particularly relevant to the donor, remains unknown.

In conclusion, it appears that assessment of the cardiovascular manifestations of TTTS can have a role in the management of TTTS by providing a useful and hopefully increasingly reliable tool to allow earlier diagnosis while providing a method for refining staging and guiding treatment. It also has a role in quantifying the success of treatment, monitoring recovery as well as the need for appropriate peri- and postnatal surveillance. As TTTS is essentially a cardiovascular disorder, it is appropriate to attempt to quantify cardiovascular involvement, there is a need for as accurate classification of the clinical picture as is possible as this is essential for clinicians both for managing the pregnancy and for counseling parents on treatment options and possible outcomes.

Recovery of functional heart disease is now assumed and appears to have an excellent prognosis, even in the most severe cases (Baschat et al., 2011) in both the short term and also, importantly, in the longer term (Halvorsen et al., 2009). Identification of those needing longer-term monitoring is important and as yet inadequately defined. Whether 
cardiovascular reprogramming takes place despite apparent recovery in utero remains to be seen (Crispi et al., 2012; Diehl et al., 2014).

Many of the studies are conflicting in terms of their findings and conclusions, further emphasizing the complexity of the nature of the cardiac involvement; there is still much to be understood on the subject (Benoit \& Baschat, 2014; Lewi et al., 2013; Moon-Grady, 2014). The impact of compromised cardiac function in terms of cerebral perfusion and longer-term neurological development is relevant and also requires further investigation. Now that perinatal survival for TTTS is improved, understanding the longer-term sequelae of TTTS has never been more important.

\section{References}

Akkermans, J., Peeters, S. H., Klumper, F. J., Lopriore, E., Middeldorp, J. M., \& Oepkes, D. (2015). Twenty-five years of fetospcopic laser coagulation in twin-twin transfusion syndrome: A systematic review. Fetal Diagnosis and Therapy, 38, 241-153.

AlRais, F., Feldstein, V. A., Srivastava, D., Gosnell, K., \& MoonGrady, A. J. (2011). Monochorionic twins discordant for congenital heart disease: A referral center's experience and possible pathophysiologic mechanisms. Prenatal Diagnosis, 31, 978-984.

Barrea, C., Alkazaleh, F., Ryan, G., McCrindle, B. W., Roberts, A., Bigras, J.-L., ... Hornberger, L. K. (2005). Prenatal cardiovascular manifestations in the twin-to-twin transfusion recipients and the impact of therapeutic amnioreduction. American Journal of Obstetrics and Gynecology, 192, 892902.

Baschat, A., Chmait, R. H., Deprest, J., Gratacos, E., Hecher, K., Kontopoulos, E., ... Ville, Y. (2011). Twin-to-twin transfusion syndrome (TTTS). Journal of Perinatal Medicine, 39, 107-112.

Baud, D., Windrim, R., Van Mieghem, T., Keunen, J., Seaward, G., \& Ryan, G. (2014). Twin-twin transfusion syndrome: A frequently missed diagnosis with important consequences. Ultrasound in Obstetrics and Gynecology, 44, 205-209.

Bebbington, M. (2010). Twin-to-twin transfusion syndrome: Current understanding of pathophysiology, in-utero therapy and impact for future development. Seminars in Fetal and Neonatal Medicine, 15, 15-20.

Benoit, R. M., \& Baschat, A. A. (2014). Twin-to-twin transfusion syndrome: Prenatal diagnosis and treatment. American Journal of Perinatology, 31, 583-594.

Berg, C., Kremer, C., Geipel, A., Kohl, T., Germer, U., \& Gembruch, U. (2006). Ductus venous blood flow alterations in fetuses with obstructive lesions of the right heart. Ultrasound in Obstetrics and Gynecology, 28, 137-142.

Chmait, R. H., Kontopoulos, E. V., \& Quintero, R. A. (2014). Sequential laser surgery for twin-twin transfusion syndrome. American Journal of Perinatology, 31, S13-S18.

Crispi, F., Figueras, F., Cruz-Lemini, M., Bartrons, J., Bijnens, B., \& Gratacos, E. (2012). Cardiovascular programming in children born small for gestational age and relationship with prenatal signs of severity. American Journal of Obstetrics and Gynecology, 207, 121e1-9.

Crispi, F., \& Gratacos, E. (2012). Fetal cardiac function: Technical considerations and potential research and clinical applications. Fetal Diagnosis and Therapy, 32, 47-64.

Crombleholme, T., Shera, D., Lee, H., Johnson, M., D’Alton, M., Porter, F., ... Young, B. (2007). A prospective randomized multicentre trial of amnioreduction versus selective fetoscopic laser photocoagulation for the treatment of severe twin-twin transfusion syndrome. American Journal of Obstetrics and Gynecology, 197, 396.e1-396.e9.

De Villiers, S. F., Slaghekke, F., Middeldorp, J. M., Walther, F. J., Oepkes, D., \& Lopriore, E. (2012). Arterio-arterial vascular anastomoses in monochorionic placentas with and without twin-twin transfusion syndrome. Placenta, 33, 652-654.

Delsing, B., Lopriore, E., Blom, N., Te Pas, A. B., Vandenbussche, F. P., \& Walther, F. J. (2007). Risk of persistent pulmonary hypertension of the neonate in twin-totwin transfusion syndrome. Neonatology, 92, 134-138.

Diehl, W., Diemert, A., \& Hecher, K. (2014). Twin-twintransfusion syndrome: Treatment and outcome. Best Practice and Research Clinical Obstetrics and Gynaecology, 28, 227-238.

Edlow, A. G., Reiss, R., Benson, C. B., Gerrol, P., \& WilkinsHaug, L. (2011). Monochorionic diamniotic twin gestations discordant for markedly enlarged nuchal translucency. Prenatal Diagnosis, 31, 299-306.

Eixarch, E., Valsky, D., Deprest, J., Baschat, A. A., Lewi, L., Ortiz, J. U., ... Gratacos, E. (2013). Preoperative prediction of the individualized risk of early fetal death after laser therapy in twin-to-twin transfusion syndrome. Prenatal $D i$ agnosis, 33, 1033-1038.

Galea, P., Barigye, O., Wee, L., Jain, V., Sullivan, M., \& Fisk, N. M. (2008). The placenta contributes to activation of the renin angiotensin system in twin-twin transfusion syndrome. Placenta, 29, 734-742.

Gapp-Born, E., Sananes, N., Weingertner, A. S., Guerra, F., Kohler, M., Fritz, G., . . Favre, R. (2014). Predictive value of cardiovascular parameters in twin-to-twin transfusion syndrome. Ultrasound in Obstetrics and Gynecology, 44, 427-433.

Gardiner, H. M., Matsui, H., Roughton, M., Greenwald, S. E., Diemert, A., Taylor, M. J., \& Hecher, K. (2014). Cardiac function in 10-year-old twins following different fetal therapies for twin-twin transfusion syndrome. Ultrasound in Obstetrics and Gynecology, 43, 652-657.

Gratacos, E., Van Schoubroeck, D., Carreras, E., Devlieger, R., Roma, E., Cabero, L., \& Deprest, J. (2002). Transient hydropic signs in the donor fetus after fetoscopic laser coagulation in severe twin-twin transfusion syndrome: Incidence and clinical relevance. Ultrasound in Obstetrics and Gynecology, 19, 449-453.

Habli, M., Cnota, J., Michelfelder, E., Salisbury, S., Schnell, B., Polzin, W., ... Crombleholme, T. (2010). The relationship between amniotic fluid levels of brain-type natriuretic peptide and recipient cardiomyopathy in twin-twin transfusion syndrome. American Journal of Obstetrics and Gynecology, 203, 404.e1-7. 
Habli, M., Michelfelder, E., Cnota, J., Wall, D., Polzin, W., Lewis, D., ... Crombleholme, T. (2012). Prevalence and progression of recipient-twin cardiomyopathy in earlystage twin-twin transfusion syndrome. Ultrasound in $\mathrm{Ob}$ stetrics and Gynecology, 39, 63-68.

Habli, M., Michelfelder, E., Livingston, J., Harmon, J., Lim, F.-Y., Polzin, W., \& Crombleholme, T. (2008). Acute effects of selective fetoscopic photocoagulation on recipient cardiac function in twin-twin transfusion syndrome. American Journal of Obstetrics and Gynecology, 199, 412.e1-6.

Halvorsen, C. P., Bilock, S. L., Pilo, C., Sonesson, S.-E., \& Norman, M. (2009). Childhood cardiac function after twinto-twin transfusion syndrome - A 10 year follow up. Acta Paediatrica, 98, 1468-1474.

Herberg, U., Bolay, J., Graeve, P., Hecher, K., Bartmann, P., \& Breuer, J. (2014). Intertwin cardiac status at 10-year followup after intrauterine laser coagulation therapy of severe twin-twin transfusion syndrome: Comparison of donor, recipient and normal values. (2014). Archives of Diseases in Childhood Fetal and Neonatal Edition, 99, F380-385.

Herberg, , U. Herberg, Gross, W., Bartmann, P., Banek, C. S., Hecher, K., \& Breuer, J. (2006). Long term cardiac follow up of severe twin to twin transfusion syndrome after intrauterine laser coagulation. Heart, 92, 95-100.

Lewi, L., Deprest, J., \& Hecher, K. (2013). The vascular anastomoses in monochorionic twin pregnancies and their clinical consequences. American Journal of Obstetrics and Gynecology, 208, 19-30.

Mahieu-Caputo, D., Meulemans, A., Martinovic, J., Gubler, M. C., Delezoide, A. L., Muller, F., ... Dommergues, M. (2005). Paradoxic activation of the renin-angiotensin system in twin-twin transfusion syndrome: An explanation for cardiovascular disturbances in the recipient. Paediatric Research, 58, 685-688.

Mahieu-Caputo, D., Salomon, L. J., Le Bidois, J., Fermont, L., Brunhes, A., Jouvet, P., ... Dommergues, M. (2003). Fetal hypertension: An insight into the pathogenesis of the twin-twin transfusion syndrome. Prenatal Diagnosis, 23, 640-645.

Matias, A., Montenegro, N., Loureiro, T., Cunha, M., Duarte, S., Freitas, D., ... Severo, M. (2010). Screening for twintwin transfusion syndrome at 11-14 weeks of pregnancy: The key role of ductus venosus blood flow assessment. Ultrasound in Obstetrics and Gynecology, 35, 142-148.

Mercanti, I., Boivin, A., Wo, B., Vlieghe, V., Le Ray, C., Audibert, F., ... Nuyt, A. M. (2011). Blood pressures in newborns with twin-twin transfusion syndrome. Journal of Perinatology, 31, 417-424.

Merz, W. M., \& Gembruch, U. (2014). Old tool — New application: Nt-proBNP in fetal medicine. Ultrasound in Obstetrics and Gynecology, 44, 377-385.

Michelfelder, E., Gottliebson, W., Border, W., Kinsel, M., Polzin, W., Livingston, J., ... Crombleholme, T. (2007). Early manifestations and spectrum of recipient twin cardiomyopathy in twin-twin transfusion syndrome: Relation to Quintero stage. Ultrasound in Obstetrics and Gynecology, 30, 965-971.
Michelfelder, E., Tan, X., Cnota, J., Divanovic, A., Statile, C., Lim, F.-Y., \& Crombleholme, T. (2015). Prevalence, spectrum, and outcome of right ventricular outflow tract abnormalities in twin-twin transfusion syndrome: A large single-center experience. Congenital Heart Disease, 10, 209-218.

Miura, K., Higashijima, A., Miura, S., Mishima, H., Yamasaki, K., Abe, S., ... Masuzaki, H. (2014). Predominantly placenta-expressed mRNAs in maternal plasma as predictive markers for twin-twin transfusion syndrome. Prenatal Diagnosis, 34, 345-349

Moon-Grady, A. J. (2014). Fetal echocardiography in twintwin transfusion syndrome. American Journal of Perinatology, 31, S31-38.

Moon-Grady, A. J., Rand, L., Lemley, B., Gosnell, K., Hornberger, K. L., \& Lee, H. (2011). Effect of selective fetoscopic laser photocoagulation therapy for twin-twin transfusion syndrome on pulmonary valve pathology in recipient twins. Ultrasound in Obstetrics and Gynecology, 37, 27-33.

Moon-Grady, A., Rand, L., Gallardo, S., Gosnell, K., Lee, H., \& Feldstein, V. (2011). Diastolic cardiac pathology and clinical twin-twin transfusion syndrome in monochorionic/diamniotic twins. American Journal of Obstetrics and Gynecology, 205, 279e1-279.e11.

O’Donoghue, K., Cartwright, E., Galea, P., \& Fisk, N. M. (2007). Stage 1 twin-twin transfusion syndrome: Rates of progression and regression in relation to outcome. Ultrasound in Obstetrics and Gynecology, 30, 958-964.

Papanna, R., Mann, L. K., Molina, S., Johnson, A., \& Moise, K. J. (2011). Changes in the recipient fetal TEI index in the peri-operative period after laser photocoagulation of placental anastomoses for twin-twin transfusion syndrome. Prenatal Diagnosis, 31, 176-180.

Pruetz, J. D., Schrager, S. M., Wang, T. V., Llanes, A., Chmait, R. H., \& Vanderbilt, D. L. (2015). Blood pressure evaluation in children treated with laser surgery for twin-twin transfusion syndrome at 2-year follow-up. American Journal of Obstetrics and Gynecology, 213, 417.e1-417.e7.

Pruetz, J. D., Slansky, M., Detterich, J., Korst, L., Llanes, A., \& Chmait, R. H. (2011). Twin-twin transfusion syndrome treated with laser surgery: Postnatal prevalence of congenital heart disease in surviving recipients and donors. Prenatal Diagnosis, 31, 973-977.

Quintero, R. (2010). Opinion. Chop, chop. Ultrasound in $\mathrm{Ob}$ stetrics and Gynecology, 36, 6-9.

Rychic, J., Tian, Z., Bebbington, M., Moldenhauer, J., Khalek, N., \& Johnson, M. (2010). Evaluation of the cardiovascular system in twin-twin transfusion syndrome: It's not about 'scores' but about 'goals' (Letter). Ultrasound in Obstetrics and Gynecology, 36, 647-651.

Rychik, J., Tian, Z., Bebbington, M., Xu, F., McCann, M., Mann, S., ... Johnson, M. (2007). The twin-twin transfusion syndrome: Spectrum of cardiovascular abnormality and development of a cardiovascular score to assess severity of disease. American Journal of Obstetrics and Gynecology, 197, 392.e1-e8.

Saunders, N. J., Snijders, R. J., \& Nicolaides, K. H. (1991). Twin-twin transfusion syndrome during the 2 nd trimester 
is associated with small intertwin haemoglobin differences. Fetal Diagnosis and Therapy, 6, 34-36.

Senat, M.-V., Deprest, J., Boulvain, M., Paupe, A., Winer, N., \& Ville, Y. (2004). Endoscopic laser surgery versus serial amnioreduction for severe twin-to-twin transfusion syndrome. New England Journal of Medicine, 351, 136-144.

Silva, S., Martins, Y., Matias, A., \& Blickstein, I. (2011). Why are monozygotic twins different?. Journal of Perinatal Medicine, 39, 195-202.

Stagnati, V., Chalouhi, G. E., Essaoui, M., Guiseppi, A., Stirnemann, J. J., Le Bidois, J., \& Ville, Y. (2015). Pulmonary stenosis in complicated monochorionic twin pregnancies: Prevalence, management and outcome. Prenatal Diagnosis, 35, 1085-1092.

Stirnemann, J. J., Mougeot, M., Proulx, F., Nasr, B., Essaoui, M., Fouron, J. C., \& Ville, Y. (2010). Profiling fetal cardiac function in twin-twin transfusion syndrome. Ultrasound in Obstetrics and Gynecology, 35, 19-27.

Stirnemann, J. J., Nasr, B., Proulx, F., Essaoui, M., \& Ville, Y. (2010). Evaluation of the CHOP cardiovascular score as a prognostic predictor of outcome in twin-twin transfusion syndrome after laser coagulation of placental vessels in a prospective cohort. Ultrasound in Obstetrics and Gynecology, 36, 52-57.

Sueters, M., Middeldorp, J. M., Vandenbussche, F. P., Teunissen, K. A., Lopriore, E., Kanhai, H. H., ... Oepkes, D. (2008). The effect of fetoscopic laser therapy on fetal cardiac size in twin-twin transfusion syndrome. Ultrasound in Obstetrics and Gynecology, 31, 158-163.

Takahashi, H., Takahashi, S., Tsukamoto, K., Ito, Y., Nakamura, T., Hayashi, S., \& Sago, H. (2012). Persistent pulmonary hypertension of the newborn in twin-twin transfusion syndrome following fetoscopic laser surgery. Journal of Maternal Fetal and Neonatal Medicine, 25, 543-545.

Van den Boom, J., Battin, M., \& Hornung, T. (2010). Twintwin transfusion syndrome, coarctation of the aorta and hypoplastic aortic arch: A case series report. Journal of Paediatrics and Child Health, 46, 76-79.

Van Mieghem, T., Done, E., Gucciardo, L., Klaritsch, P., Allegaert, K., Van Bree, R., ... Deprest, J. (2010). Amniotic fluid markers of fetal cardiac dysfunction in twin-twin transfusion syndrome. American Journal of Obstetrics and Gynecology, 202, 48.e1-7.
Van Mieghem, T., Klaritsch, P., Done, E., Gucciardo, L., Lewi, P., Verhaeghe, J., ... Deprest, J. (2009). Assessment of fetal cardiac function before and after therapy for twin-to-twin transfusion syndrome. American Journal of Obstetrics and Gynecology, 200, 400.e1-7.

Van Mieghem, T., Lewi, L., Gucciardo, L., DeKoninck, P., Van Schoubroeck, D., Devlieger, R., \& Deprest, J. (2010). The fetal heart in twin-to-twin transfusion syndrome. International Journal of Pediatrics, Article ID 379792.

Van Mieghem, T., Martin, A. M., Weber, R., Barrea, C., Windrim, R., Hornberger, L. K., ... Ryan, G. (2013). Fetal cardiac function in recipient twins undergoing laser ablation of placental anastomoses for Stage $1 \mathrm{~V}$ twin-twin transfusion syndrome. Ultrasound in Obstetrics and Gynecology, 42, 64-69.

Villa, C. R., Habli, M., Votava-Smith, J. K., Cnota, J. F., Lim, F.-Y., Divanovic, A. A., ... Michelfelder, E. C. (2014). Assessment of fetal cardiomyopathy in early-stage twin-twin transfusion syndrome: Comparison between commonly reported cardiovascular assessment scores. Ultrasound in $\mathrm{Ob}$ stetrics and Gynecology, 43, 646-651.

Ville, Y. (2007). Opinion. Twin-to-twin transfusion syndrome: Time to forget the Quintero staging system?. Ultrasound in Obstetrics and Gynecology, 30, 924-927.

Weber, M. A., \& Sebire, N. J. (2010). Genetics and developmental pathology of twinning. Seminars in Fetal and Neonatal Medicine, 15, 313-318.

Yamamoto, M., Nasr, B., Ortqvist, L., Bernard, J.-P., Takahashi, Y., \& Ville, Y. (2007). Intertwin discordance in umbilical venous volume flow: A reflection of blood volume imbalance in twin-to-twin transfusion syndrome. Ultrasound in $\mathrm{Ob}$ stetrics and Gynecology, 29, 317-320.

Zanardini, C., Prefumo, F., Fichera, A., Botteri, E., \& Frusca, T. (2014). Fetal cardiac parameters for prediction of twinto-twin transfusion syndrome. Ultrasound in Obstetrics and Gynecology, 44, 434-440.

Zhao, D. P., Cambiaso, O., Otano, L., Lewi, L., Deprest, J., Sun, L. M., ... Lopriore, E. (2015). Veno-venous anastomoses in twin- twin transfusion syndrome: A multicentre study. Placenta, 36, 911-914.

Zhao, D. P., Cohen, D., Middeldorp, J. M., Klumper, F. J., Haak, M. C., Oepkes, D., \& Lopriore, E. (2014). The role of venovenous anastomoses in twin-twin transfusion syndrome. Placenta, 35, 334-336. 